\title{
Electrospray Tandem Mass Spectrometry Analysis of S- and N-Nitrosopeptides: Facile Loss of NO and Radical-Induced Fragmentation
}

\author{
Gang Hao* and Steven S. Gross \\ Department of Pharmacology, Weill Medical College of Cornell University, New York, New York, USA
}

\begin{abstract}
The covalent addition of nitric oxide (NO) to protein thiols, a posttranslational modification termed S-nitrosation, is a ubiquitous event that modulates diverse cellular processes. The in vivo addition of NO to protein amines (N-nitrosation) has also been described and may similarly modify protein structure and function. While mass spectrometry has been employed for identification of nitrosoproteins, little is known about how S- and N-nitrosopeptides fragment. Such knowledge is important for its potential to inform on sites of protein nitrosation. Here we used electrospray tandem mass spectrometry to elucidate collisioninduced dissociation (CID) features of S- and N-nitrosopeptide ions. We show that S- and $\mathrm{N}$-nitrosopeptide ions readily lose $\mathrm{NO}$, giving rise to species that contain thiyl and aminyl radicals, respectively. Fragmentation $\left(\mathrm{MS}^{3}\right)$ of these radical peptide ions revealed an atypical pattern, characterized by the cleavage of select ${ }^{\alpha} \mathrm{C}-\mathrm{C}$ and $\mathrm{N}-{ }^{\alpha} \mathrm{C}$ bonds, rather than the more usual cleavage of amide bonds that result in $\mathrm{b}$ - and $\mathrm{y}$-ions. These unanticipated fragmentation patterns are reconciled by radical-mediated abstraction of hydrogen from $\beta$-carbon followed by $\beta$-fragmentation. For thiyl radical peptides, we also observed dominant loss of $\mathrm{SH}$ and $\mathrm{CH}_{2} \mathrm{SH}$ from the Cys side-chain. Our findings provide new insights into the gas-phase chemistry of NO-modified peptide ions and suggest an unusual fragmentation pattern that may aid in future MS-based attempts to define the nitrosoproteome. (J Am Soc Mass Spectrom 2006, 17, 1725-1730) (c) 2006 American Society for Mass Spectrometry
\end{abstract}

$\mathrm{N}$ itric oxide (NO) is a gaseous signaling molecule that plays pivotal roles in diverse physiological processes, including vascular homeostasis, neurotransmission, and host defense [1]. Many actions of NO are mediated by the covalent addition of $\mathrm{NO}$ to protein Cys thiols, a reaction referred to as either S-nitrosation or S-nitrosylation [2]. S-nitros(yl)ation has emerged as a ubiquitous posttranslational protein modification that modulates the functions of a wide array of proteins [2,3]. With the advent of mass spectrometry-based proteomic detection methods, new S-nitrosoproteins are being recognized at an accelerating rate $[4,5]$. More recently, N-nitrosation of protein amines has also been reported to occur endogenously and may contribute to $\mathrm{NO}$ bioactivities $[6,7]$. Like S-nitrosation, N-nitrosation is inferred to be widely distributed, stimulus-evoked, and linked to cell redox state [7]. Despite potential importance, mass spectrometry has not been applied for characterization of $\mathrm{N}$-nitrosoproteins and the identities of in vivo N-

Published online September 6, 2006

Address reprint requests to Dr. S. Gross, Department of Pharmacology, Weill Medical College of Cornell University, 1300 York Ave., Room LC-428, New York, NY 10021, USA. E-mail: ssgross@med.cornell.edu

* Also at Altus Pharmaceuticals, 195 Albany Street, Cambridge, MA 02139, USA. nitrosoproteins remain unknown. Nonetheless, it has been shown with model peptides that indole nitrogens of tryptophan residues can readily undergo NO addition $[8-10]$.

Identification of the site of $\mathrm{NO}$ addition on a Snitrosoprotein constitutes a crucial step in elucidating how NO modification of a protein impacts its structure and function. To date, MS-based identifications of Snitrosation sites have been either deduced from a mass shift of $29 \mathrm{Da}$ (NO minus hydrogen) [11, 12] or via an indirect tagging approach that converts a S-nitrosothiol into a biotinylated thiol [5]. It is notable that $\mathrm{S}-\mathrm{NO}$ and $\mathrm{N}-\mathrm{NO}$ bonds are labile in solution-phase, where UV irradiation elicits homolytic cleavage, producing $\mathrm{NO}$ and thiyl or aminyl radicals [13,14]. Disruption of the $\mathrm{S}-\mathrm{NO}$ bond on S-nitrosopeptides occurs readily in the gas phase of a mass spectrometer via in-source decay [15]. Nevertheless, prior MS studies have not investigated how the odd-electron radical peptide ions further fragment. This knowledge could be useful for identification of novel nitrosation sites if more favorable $\mathrm{S}-\mathrm{NO}$ or $\mathrm{N}-\mathrm{NO}$ dissociation were to suppress the formation of backbone cleavage products. Given the lack of knowledge about the ion chemistry of nitrosopeptide species, the present study seeks to elucidate the fragmentation reactions of $\mathrm{S}$ - and $\mathrm{N}$-nitrosopeptides 
in an ion trap mass spectrometer. Characteristic fragmentation behaviors revealed by this study provide a guide for the interpretation of MS analyses that seek to identify novel protein nitrosation sites.

\section{Experimental}

\section{Materials}

Human hemoglobin was purchased from Sigma Chemical Co. (St. Louis, MO) and human $\alpha$-melanocyte stimulating hormone (MSH; Acetyl-Ser-Tyr-Ser-MetGlu-His-Phe-Arg-Trp-Gly-Lys-Pro-Val-amide) was purchased from Peptides International (Louisville, KY). All other chemicals and reagents were purchased from Sigma.

\section{Generation of S-Nitrosopeptide and N-Nitrosopeptide}

Human hemoglobin was dissolved in $20 \mathrm{mM}$ Tris- $\mathrm{HCl}$, $\mathrm{pH}$ 7.6, $1 \mathrm{mM}$ EDTA and $0.1 \mathrm{mM}$ neocuproine to achieve a final concentration of $2 \mathrm{mg} / \mathrm{ml}$. To this hemoglobin solution $(90 \mu \mathrm{L}), 1 \mathrm{mM}$ GSNO was added $(10 \mu \mathrm{L})$ and samples were incubated at $37^{\circ} \mathrm{C}$ for $30 \mathrm{~min}$ in the dark. To isolate hemoglobin free of unreacted GSNO, protein was precipitated with two volumes of iced-acetone and pelleted by centrifugation at $2000 \times g$ for $5 \mathrm{~min}$. Protein pellets were resuspended in $100 \mu \mathrm{L}$ of trypsinization buffer, comprising $5 \mathrm{mM} \mathrm{NH}_{4} \mathrm{HCO}_{3}$ and $10 \%$ acetonitrile $(\mathrm{ACN})$. Sequencing-grade trypsin (Promega; $1 \mu \mathrm{g}$, Madison, WI) was added and proteolysis was performed at $37^{\circ} \mathrm{C}$ for $1 \mathrm{~h}$ in the dark. The digest was diluted 500 -fold with $0.1 \%$ trifluoroacetic acid (TFA) solution and then subjected to LC-MS/MS analysis. For peptide N-nitrosation, $\alpha$-melanocyte stimulating hormone (MSH) was dissolved in $0.1 \%$ TFA at a concentration of $10 \mathrm{pmol} / \mu \mathrm{L}$ and sodium nitrite was added to a final concentration of $1 \mathrm{mM}$. The reaction mixture was incubated at $37^{\circ} \mathrm{C}$ for $1 \mathrm{~h}$ in the dark and then diluted 100-fold for analysis by LC-MS/MS. Identical quantities of untreated hemoglobin and MSH were processed as above to serve as negative controls.

\section{Instrumentation}

Liquid chromatography-tandem mass spectrometry analysis (LC-MS/MS) was performed using an 1100 series LC/MSD Ultra ion trap mass spectrometer (Agilent Technologies, Palo Alto, CA). The system was equipped with an Agilent Chip Cube interface and a silicon wafer "chip-column" that integrates a C18 enrichment column, C18 resolving column, and nanospray emitter. Samples were loaded on the enrichment column at a flow rate of $5 \mu \mathrm{L} / \mathrm{min}$ and then resolved at a flow rate of $0.3 \mu \mathrm{l} / \mathrm{min}$ on $40 \mathrm{~mm} \times 75 \mu \mathrm{M}$ ZORBAX 300 C18 column (Agilent). The LC gradient was 10 to $40 \%$ Solvent B for $30 \mathrm{~min}$, followed by 40 to $90 \%$ Solvent B for $20 \mathrm{~min}$. Solvent A contained $0.1 \%$ formic acid in
$3 \% \mathrm{ACN}$ and Solvent B contained $0.1 \%$ formic acid in $90 \%$ ACN. ESI conditions included a needle voltage of $2 \mathrm{kV}$, nitrogen gas flow rate of $4 \mathrm{~L} / \mathrm{min}$, and a capillary temperature of $300{ }^{\circ} \mathrm{C}$. MS spectra were acquired at a scan speed of $8000 \mathrm{~m} / \mathrm{z} / \mathrm{s}$ and the four most intense precursor ions were selected for MS/MS fragmentation. $\mathrm{MS}^{3}$ was triggered on MS/MS product ions that met the following two criteria: (1) the single most intense ion among all observed product ions; (2) an $\mathrm{m} / \mathrm{z}$ that is equal to either 15 or $10 \mathrm{Da}$ less than the parent ion (i.e., loss of NO from either the doubly- and triply-charged peptide ion). The skimmer voltage was $20 \mathrm{~V}$, and the fragmentation amplitude was $1.3 \mathrm{~V}$. The SmartFrag function was activated for automatic ramping of the fragmentation amplitude until the entire precursor ion was dissociated.

\section{Results and Discussion}

Human hemoglobin was selected as a model protein to study S-nitrosation. Upon exposure to NO, both in vitro and in vivo, hemoglobin undergoes Snitrosation on Cys- $\beta 93$ [12]. Notably, this site of NO addition has been the subject of intense investigation, owing to its important role in facilitating oxygen delivery to hypoxic tissues [16]. Hemoglobin was incubated with the NO donor, S-nitrosoglutathione (GSNO) to induce S-nitrosothiol formation. After removal of unreacted GSNO, hemoglobin was trypsinized and the resulting peptide mixture was resolved and analyzed by LC-MS/MS. Only two S-nitrosopeptides ions could be detected and each was reconciled to contain Snitroso Cys $\beta$-93-these are the doubly-charged peptide ions arising from GFATLSELHC ${ }_{\mathrm{NO}} \mathrm{DK}$ (peptide S2), and the triply-charged peptide ion with one missed tryptic cleavage site, GTFATLSELHC ${ }_{\text {NO }}$ DKLHVDPENFR (peptide S3).

Synthetic human $\alpha$-melanocyte stimulating hormone (MSH), following treatment with acidified nitrite, was studied as a model system for elucidation of $\mathrm{N}$-nitrosopeptide fragmentation. Since MSH is Nblocked and contains lone Arg and Trp residues, it possesses one each of primary and secondary amine nitrogen atoms as possible sites for $\mathrm{NO}$ addition. Consistent with an earlier finding [10], N-nitrosation was not observed following treatment of MSH with GSNO. Nonetheless, upon exposure of MSH to acidified nitrite as the NO-donor, a nitrosated MSH peptide acetylSYSMEHFRW $_{\text {NO GKPV-amide was detected as both }}$ doubly-charged (peptide N2) and triply-charged (peptide N3) species. CID MS/MS spectra of nitrosopeptides S2, S3, N2, and N3 are shown in Figure 1a and $\mathrm{d}$, and Figure $2 \mathrm{a}$ and $\mathrm{d}$, respectively. Note that in each case the spectra are dominated by a single ion species, which can be reconciled by the loss of NO ( -15 Da for doubly-charged peptide ions and $-10 \mathrm{Da}$ for triplycharged peptide ions). Significant NO loss was also observed by in-source decay of the corresponding parent ions (data not shown). These observations affirm the 


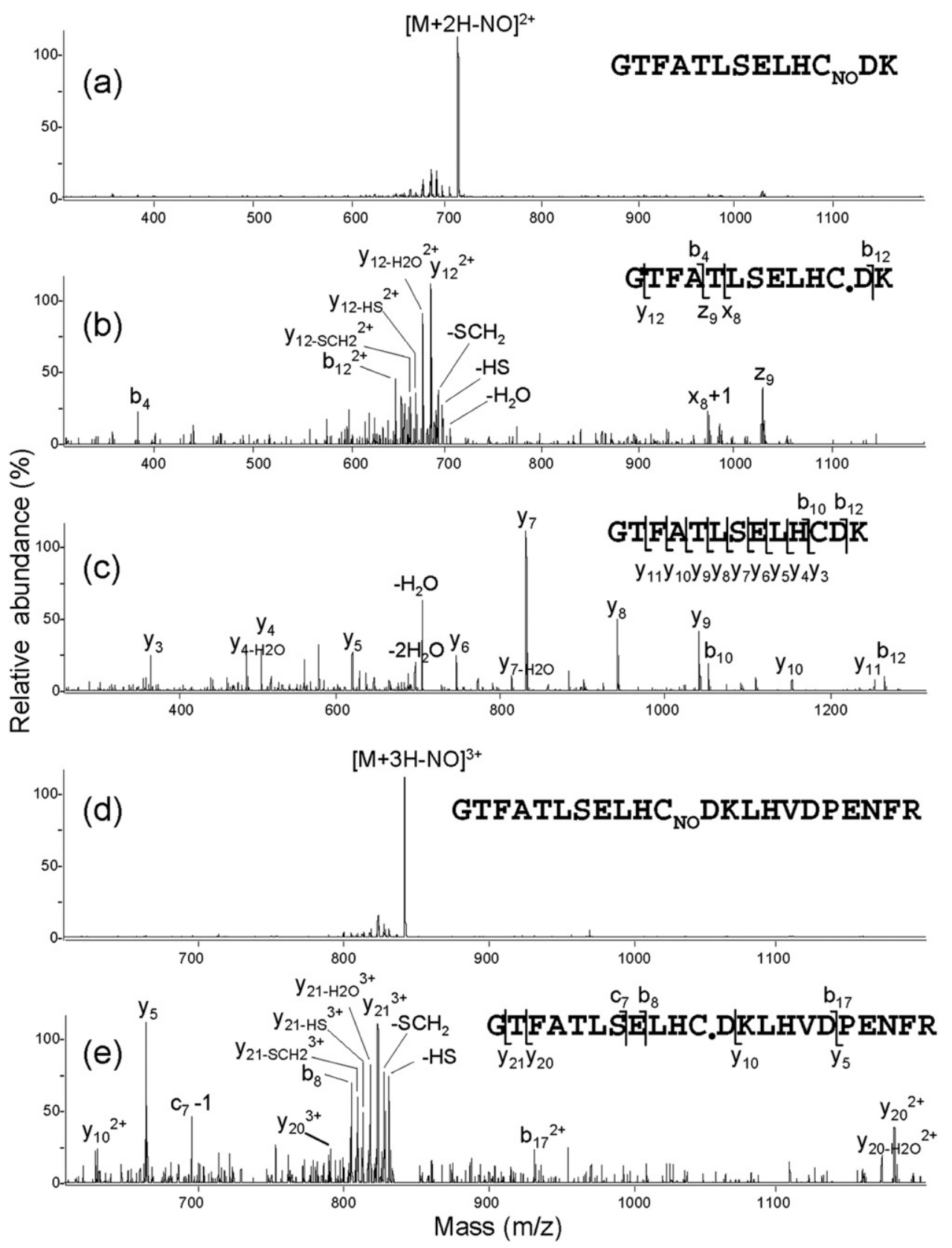

Figure 1. CID fragmentation spectra of S-nitrosopeptides from human hemoglobin tryptic digest. (a) MS/MS spectrum of doubly charged S-nitrosopeptide GFATLSELHC ${ }_{\mathrm{NO}} \mathrm{DK}$, (b) MS3 spectrum of doubly charged thiyl radical-peptide GFATLSELHC.DK, (c) MS/MS spectrum of doubly charged, native peptide GFATLSELHCDK, (d) MS/MS of triply charged S-nitrosopeptide GTFATLSELHCNODKLHVDPENFR, (e) MS3 spectrum of triply charged thiyl radical-peptide GTFATLSELHC. DKLHVDPENFR.

highly labile nature of Cys S-NO and Trp N-NO bonds in cognate peptides.

Given the limited product ions observed in the MS/MS spectra of S-NO and N-NO peptides, CID of the neutral loss peak (i.e., $\mathrm{MS}^{3}$ ) was performed to elucidate fragmentation products and deduce structural features of parent ions. $\mathrm{MS}^{3}$ analyses were automatically triggered by the NO loss event, as described in the Experimental section. The dominant product ions arising from NO loss were reconciled to be odd-electron species, possessing either Cys-thiyl or Trp-aminyl radicals. The product spectra of these radical-peptides S2, S3, N2, and N3 are shown in Figure $1 b$ and e, and Figure $2 \mathrm{~b}$ and $\mathrm{e}$, respectively. For thiyl radical peptides $\mathrm{S} 2$ and $\mathrm{S} 3$, loss of both $\mathrm{SH}$ and $\mathrm{CH}_{2} \mathrm{~S}$ from the Cys side chain was observed, whereas no significant side-chain losses were detected for aminyl radical peptides N2 and N3. Whereas $\mathrm{SH}$ and $\mathrm{CH}_{2} \mathrm{~S}$ losses were previously described for $\mathrm{CID}$ of a $\mathrm{Cu}(\mathrm{II})$-generated thiyl radical containing tripeptide (GCR) [17], our findings indicate 

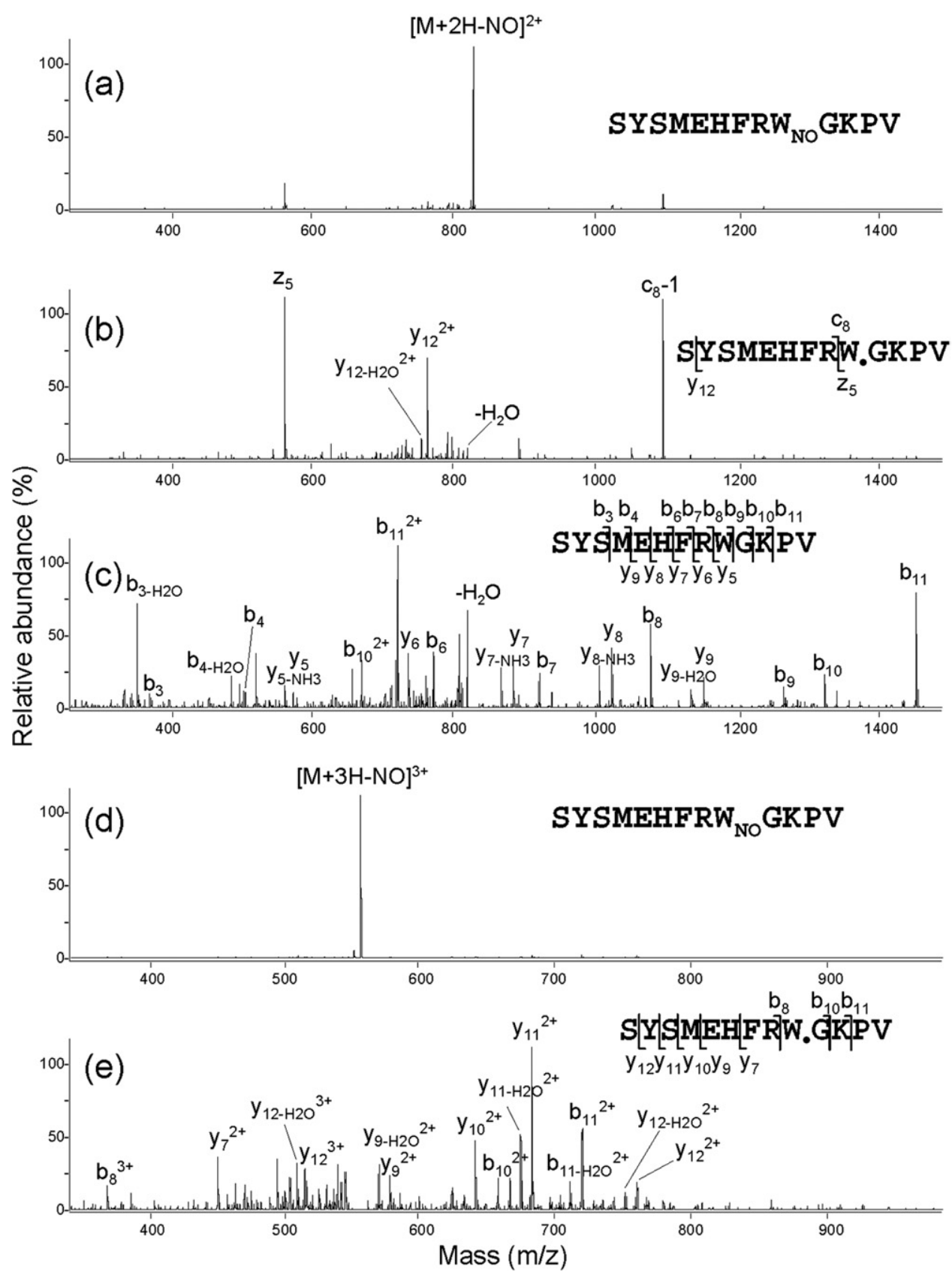

Figure 2. CID fragmentation spectra of N-nitrosopeptides derived from $\alpha$-Melanocyte stimulating hormone. (a) MS/MS spectrum of doubly charged N-nitroso-peptide acetyl-SYSMEHFRW ${ }_{\text {NOGKPV- }}$ amide, (b) MS3 spectrum of doubly charged aminyl radical-peptide acetyl-SYSMEHFRW.GKPVamide, (c) MS/MS of doubly charged, native peptide acetyl-SYSMEHFRWGKPV-amide, (d) MS/MS

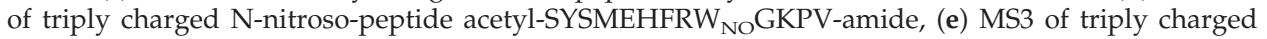
aminyl radical-peptide acetyl-SYSMEHFRW.GKPV-amide.

that S-nitrosation efficiently promotes thiyl radical formation without the requirement of a transition-metal.

Doubly charged radical peptides S2 and N2 generated far fewer amide bond fragmentation products (i.e., $\mathrm{b}$ - and y-ions) than the corresponding native peptides (Figures 1c and 2c), demonstrating that the unpaired electron can dramatically alter the fragmentation process. Interestingly, apart from side-chain cleavages, several ${ }^{\alpha} \mathrm{C}-\mathrm{C}$ and $\mathrm{N}-{ }^{\alpha} \mathrm{C}$ dissociation products were observed for radical peptides S2 and N2: x8 +1 and z9 ions in Figure $1 b$, and $c 8-1$ and $z 5$ ions dominate in Figure $2 b$. These ion types are commonly observed with electron capture dissociation (ECD) [18] and also produced by CID of aminyl and carbon radical-precursor species that have been introduced into peptides by chemical conjugation $[19,20]$. The proposed fragmentation pathway for the latter involves the radical abstraction of hydrogen from a $\beta$-carbon, followed by $\beta$ 
<smiles>[R]NCC1(C([R])=O)CCC1[R]</smiles><smiles>CCNPC</smiles>

(c-1)

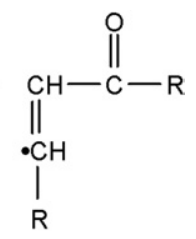

z<smiles>[R]NC1CCC(C([R])=O)C1[R]</smiles><smiles>[R]C=CNN[R]</smiles>

Scheme 1

fragmentation on either side of $\alpha-\mathrm{C}$ to generate $\mathrm{a} / \mathrm{x}+1$ or $c-1 / z$ ions [20]. This general mechanism is depicted in Scheme $\mathbf{1}$ to rationalize the unusual fragmentation pattern observed herein for nitrosopeptide-generated thiyl- and aminyl-radical ions.

Formation of observed ${ }^{\alpha} \mathrm{C}-\mathrm{C}$ and $\mathrm{N}-{ }^{\alpha} \mathrm{C}$ dissociation products are likely to be initiated by intramolecular radical-triggered hydrogen abstraction in peptide ions S2 and N2 and subsequent cleavage of the peptide backbone. Findings suggest that the thiyl radical, produced by loss of NO from peptide S2, preferentially abstracts hydrogen from a Thr side chain that is six residues distant; loss of this hydrogen then promotes peptide cleavage on either side of the Thr residue, yielding the observed $x 8+1$ and $z 9$ ions (Figure $1 b$ ). In contrast, Trp-aminyl radical formation by NO loss from peptide ion N2 apparently results in the abstraction of a local hydrogen and subsequent peptide cleavage on N-terminal side of Trp, yielding c8-1 and z5 ions (Figure 2b). The difference between thiyl and aminyl radical in terms of local versus remote hydrogen abstraction can be explained by the relative bond dissociation energies (BDE) of abstracted hydrogen atoms. The BDE of $\mathrm{S}-\mathrm{H}$ bond $(81 \mathrm{kcal} / \mathrm{mol})$ is significantly lower than $\mathrm{C}-\mathrm{H}$ bond $(99 \mathrm{kcal} / \mathrm{mol})$, explaining why the thiyl radical does not readily abstract $H$ from carbon atoms. Instead, a thiyl sulfur can abstract more looselybound hydrogens from certain side chains. Notably, our observation of cleavage on either side of Thr (Figure 1b) is in accord with rate constant measurements revealing that the most facile hydrogen abstraction by protein thiyl radicals is from the $\beta$-carbon of Thr and Ser [21]. On the other hand, the $\mathrm{N}-\mathrm{H}$ bond has a BDE close to $\mathrm{C}-\mathrm{H}$ (93 versus $99 \mathrm{kcal} / \mathrm{mol}$ ) and therefore a Trp aminyl-radical is capable of direct abstraction of hydrogen from its own $\beta$-carbon, explaining the prominent $\mathrm{c} 8$ -1 and z5 ions observed in Figure $2 b$.

The CID fragmentation patterns of radical peptides derived from nitrosopeptide S3 and N3, both triplycharged, provide further mechanistic insights (Figures 1e and 2e, respectively). Notably, S3 produces the y21 ion, also observed with peptide $\mathrm{S} 2$ as y12 ion, as well as intense $\mathrm{y} 5$ and b12 ions that are explained by the well-recognized gas-phase instability of the Asp-Pro bond. Additionally, a c7 - 1 ion was observed which presumably arises from $\beta$-cleavage at a Glu residue three residues away from Cys. The radical peptide N3 showed extensive amide bond cleavage, with a nearcomplete array of $y$-ions observed (Figure 2e). This more complete amide bond cleavage of peptide N3 can be attributed to the charge state; the additional proton on N3 is mobile, rather than sequestered by Arg and Lys, as in peptide N2 and. therefore. free to induce amide bond cleavage. These findings suggest that the radical-promoted fragmentation pathway competes kinetically with the charge-directed pathway, and the extent of protonation is a major determinant of which pathway predominates.

\section{Conclusions}

Collectively, we demonstrated that both S- and Nnitrosopeptides undergo facile neutral loss of $\mathrm{NO}$ under CID. Moreover, the radical site produced upon NO loss can elicit ${ }^{\alpha} \mathrm{C}-\mathrm{C}$ and $\mathrm{N}-{ }^{\alpha} \mathrm{C}$ bond cleavages at specific residues that are most capable of hydrogen transfer, yielding hallmark a/x and c/z types of ions. Additionally, in the case of S-nitrosopeptides, side-chain loss from Cys predominates with CID. A systematic study of nitrosopeptides will be necessary to confirm that these trends are generically applicable, and to more completely define the influence of flanking residues on radical peptide ion fragmentation. This knowledge could prove valuable for improved MS analyses of an everincreasing number of physiologically-relevant NO-modified proteins.

\section{Acknowledgments}

The authors thank Dr. Moo-Jin Suh at the Pharmacology Department of Weill Cornell Medical College for helpful discussions. This work is supported by NIH grants HL80702 and HL46403.

\section{References}

1. Nathan, C. The Moving Frontier in Nitric Oxide-Dependent Signaling. Sci. STKE 2004, pe52.

2. Hess, D. T.; Matsumoto, A.; Kim, S. O.; Marshall, H. E.; Stamler, J. S. Protein S-Nitrosylation: Purview and Parameters. Nat. Rev. Mol. Cell. Biol. 2005, 6, 150-166.

3. Lane, P.; Hao, G.; Gross, S. S. S-Nitrosylation is Emerging as a Specific and Fundamental Posttranslational Protein Modification: Head-toHead Comparison with O-Phosphorylation. Sci. STKE 2001, RE1.

4. Jaffrey, S. R.; Erdjument-Bromage, H.; Ferris, C. D.; Tempst, P.; Snyder, S. H. Protein S-Nitrosylation: A Physiological Signal for Neuronal Nitric Oxide. Nat. Cell. Biol. 2001, 3, 193-197.

5. Hao, G.; Derakhshan, B.; Shi, L.; Campagne, F.; Gross, S. S. SNOSID, a Proteomic Method for Identification of Cysteine S-Nitrosylation Sites in Complex Protein Mixtures. Proc. Natl. Acad. Sci. U.S.A. 2006, 103, 1012-1017.

6. Rassaf, T.; Bryan, N. S.; Kelm, M.; Feelisch, M. Concomitant Presence of N-Nitroso and S-Nitroso Proteins in Human Plasma. Free Rad. Biol. Med. 2002, 33, 1590-1596.

7. Bryan, N. S.; Rassaf, T.; Maloney, R. E.; Rodriguez, C. M.; Saijo, F.; Rodriguez, J. R.; Feelisch, M. Cellular Targets and Mechanisms of Nitros(yl)ation: An Insight into Their Nature and Kinetics in Vivo. Proc. Natl. Acad. Sci. U.S.A. 2004, 101, 4308-4313. 
8. Kirsch, M.; Fuchs, A.; de Groot, H. Regiospecific Nitrosation of NTerminal-Blocked Tryptophan Derivatives by N2O3 at Physiological pH. J. Biol. Chem. 2003, 278, 11931-11936.

9. Zhang, Y. Y.; Xu, A. M.; Nomen, M.; Walsh, M.; Keaney, J. F., Jr.; Loscalzo, J. Nitrosation of Tryptophan Residue(s) in Serum Albumin and Model Dipeptides. Biochemical Characterization and Bioactivity. J. Biol. Chem. 1996, 271, 14271-14279.

10. Sonnenschein, K.; de Groot, H.; Kirsch, M. Formation of S-Nitrosothiols from Regiospecific Reaction of Thiols with N-Nitrosotryptophan Derivatives. J. Biol. Chem. 2004, 279, 45433-45440.

11. Mirza, U. A.; Chait, B. T.; Lander, H. M. Monitoring Reactions of Nitric Oxide with Peptides and Proteins by Electrospray Ionization-Mass Spectrometry. J. Biol. Chem. 1995, 270, 17185-17188.

12. Ferranti, P.; Malorni, A.; Mamone, G.; Sannolo, N.; Marino, G. Characterization of S-Nitrosohaemoglobin by Mass Spectrometry. FEBS Lett. 1997, 400, 19-24.

13. Singh, R. J.; Hogg, N.; Joseph, J.; Kalyanaraman, B. Mechanism of Nitric Oxide Release from S-Nitrosothiols. J. Biol. Chem. 1996, 271, 1859618603.

14. Zhu, X. Q.; He, J. Q.; Li, Q.; Xian, M.; Lu, J.; Cheng, J. P. N-NO Bond Dissociation Energies of N-Nitroso Diphenylamine Derivatives and Their Radical Anions. J. Org. Chem. 2000, 65, 6729-6735.
15. Kaneko, R.; Wada, Y. Decomposition of Protein Nitrosothiolsin MatrixAssisted Laser Desorption/Ionization and Electrospray Ionization Mass Spectrometry. J. Mass Spectrom. 2003, 38, 526-530.

16. Stamler, J. S.; Jia, L.; Eu, J. P.; McMahon, T. J.; Demchenko, I. T.; Bonaventura, J.; Gernert, K.; Piantadosi, C. A. Blood Flow Regulation by S-Nitrosohaemoglobin in the Physiological Oxygen Gradient. Science. 1997, 276, 2034-2037.

17. Wee, S.; O'Hair, R. A.; McFadyen, W. D. Gas-Phase Ligand Loss and Ligand Substitution Reactions of Platinum(II) Complexes of Tridentate Nitrogen Donor Ligands. Rapid Commun. Mass Spectrom. 2004, 18, 1221-1226.

18. Zubarev, R. A. Reactions of Polypeptide Ions with Electrons in the Gas Phase. Mass Spectrom. Rev. 2003, 22, 57-77.

19. Masterson, D. S.; Yin, H.; Chacon, A.; Hachey, D. L.; Norris, J. L.; Porter, N. A. Lysine Peroxycarbamates: Free Radical-Promoted Peptide Cleavage. J. Am. Chem. Soc. 2004, 126, 720-721.

20. Hodyss, R.; Cox, H. A.; Beauchamp, J. L. Bioconjugates for Tunable Peptide Fragmentation: Free Radical Initiated Peptide Sequencing (FRIPS). J. Am. Chem. Soc. 2005, 127, 12436-12437.

21. Nauser, T.; Pelling, J.; Schoneich, C. Thiyl Radical Reaction with Amino Acid Side Cchains: Rate Constants for Hydrogen Transfer and Relevance for Posttranslational Protein Modification. Chem. Res. Toxicol. 2004, 17, 1323-1328. 